\title{
CLIMA E SÍTIO NA ZONA DA MATA MINEIRA: UMA ANÁLISE EM EPISÓDIOS DE VERÃO
}

\author{
FIALHO, Edson Soares - fialho@ufv.br \\ Doutor em Geografia - Bioclima / Univ Federal de Viçosa (Brasil) \\ ALVES, Rafael de Souza - rafael.s.alves@ufv.br \\ Graduando em Geografia - Bioclima / Univ Federal de Viçosa (Brasil) \\ LOPES, Diego Ingran - diego.lopes@ufv.br \\ Graduando em Geografia - Bioclima / Univ Federal de Viçosa (Brasil)
}

\begin{abstract}
Resumo
Nos estudos da relação entre fatores e elementos do clima a topografia tem um papel relevante na definição do campo termohigrométrico. Porém, esse tipo de estudo na escala sub-regional, no âmbito da ciência geográfica, vem sendo pouco desenvolvido. Em razão disso, o presente trabalho procura avaliar a influência do sítio sobre a variação termohigrométrica, ao longo do percurso Ponte Nova e Ubá, com $120 \mathrm{~km}$ de distância e uma variação altimétrica de cerca de 400 metros. Para isso, foram realizados experimentos de campo na estação de verão, sob condições de tempo estável, durante os dias 27 e 28 de janeiro e 2 e 3 de fevereiro de 2011. Dentre os resultados preliminares para os episódios de verão, pode-se observar que a diferença máxima entre os pontos de registro foi de $10,2^{\circ} \mathrm{C}$ entre Viçosa $\left(30,8^{\circ} \mathrm{C}\right)$ e Ubá $\left(41,0^{\circ} \mathrm{C}\right)$, às $15: 00$ horas do dia 27 de janeiro de 2011 , bem como nos demais dias dos experimentos. Além disso, pode-se verificar também que nem sempre as maiores cidades, como Viçosa e Ubá, são as que apresentam as maiores temperaturas ao longo do dia. Foi possível observar que Teixeiras e Visconde do Rio Branco se destacam quanto ao registro das maiores temperaturas.
\end{abstract}

Palavras chave: Topoclima, Sítio e Zona da Mata Mineira.

CLIMATE AND SITE IN ZONA DA MATA MINEIRA: EPISODES IN AN ANALYSIS OF SUMMER

\section{Abstract}

In studies concerning therelationship between climate factors and elements the topography has a significant role in defining the thermohygrometer field. However, within the geographical science, this type of study, in sub-regional scale, has been poorly developed. The objectives of the present paper is to analyse the influence of site configuration in the thermohygrometer air conditions from five cities placed in the Zona da Mata Mineira, along the route Ponte Nova - Ubá $(120 \mathrm{~km})$ and a variation in height of about 400 meters. Field experiments were conducted in the summer season, in stable weather conditions during the 27th and 28 January and 2 February 3, 2011. Preliminary results indicate a maximum difference of $10.2^{\circ} \mathrm{C}$ in the study area, between Viçosa $\left(30,8^{\circ} \mathrm{C}\right)$ and Ubá $\left(41,0^{\circ} \mathrm{C}\right), 15: 00 \mathrm{pm}$ on January 27,2011 . It was found that not all the major cities, as Viçosa and Ubá, are those with higher temperatures throughout the day; it could also be observed that the cities of Visconde do Rio Branco and Teixeira stand out on the track of higher temperatures.

Keywords: Topoclima, Site, Zona da Mata Mineira, Brazil.

\section{Introdução}

A preocupação com as questões climáticas vem ganhando relevância nos mais variados meios de informação existentes na atualidade, sendo abordadas em diversas mídias, tais como telejornais, jornais impressos, revistas científicas, programas educativos, redes sociais, dentre outros.

O clima quando abordado pela mídia é, geralmente, enfocado na escala global, a partir da primícia do aquecimento, sendo raras as exceções. 0 aquecimento global nesse contexto é veiculado como decorrência da ação inconseqüente do ser humano, que causará danos ao mundo e a todos habitantes, pondo-se a vista um colapso. Esse é o caminho pelo qual se dá o sensacionalismo que vez por outra surge ao lado das discussões referentes a clima, onde os conceitos e argumentos são mais aceitos do 
que compreendidos por grande parcela da população, dentre eles o próprio conceito de clima, como apontado por Fialho (2007) e Collischonn e Fialho (2007).

Não se busca aqui propagar que os debates sobre as mudanças climáticas globais sejam desnecessárias para o atual contexto histórico, tão pouco dizer em que medida a ação humana está, ou não, gerando modificações no clima do planeta, que por sua vez é um dos grandes desafios colocados à ciência no momento.

No entanto, como bem coloca Jardim (2010), a capacidade do homem em modificar o clima é limitada, se restringido a determinados níveis escalares. É na escala do local, ao nível das cidades, que as ações humanas têm gerado significativas modificações no clima e alavancado problemas, principalmente, relacionados a saúde. Apesar disso, poucos são os momentos em que as discussões envolvendo o clima perpassam por esse campo.

O início dos estudos do clima das cidades brasileiras ocorreu na década de 1970 , com enfoque às condições termohigrométricas, nas grandes áreas urbanas. Quanto às cidades de pequeno e médio porte, tais estudos ainda são insuficientes, apesar de um processo de expansão recente, sendo necessário ampliá-los, uma vez que muitas dessas cidades já apresentam problemas ambientais preocupantes (MENDONÇA, 2003a, 2003b).

De acordo com Monteiro (2003), o clima urbano enquanto componente da qualidade ambiental, não pode ser julgado insignificante para o mundo moderno. Por isso, diz o autor que não caberia precisar a partir de qual grau de urbanização e de características geoecológicas seria pertinente a realização de trabalho sobre clima urbano, tão pouco a utilização do termo. Além do mais, segundo Landsberg (2006, p. 95) "[...] é muito difícil decidir de forma objetiva a partir de que densidade de população e edificações alguma influência sobre o clima começa a ser notada".

Por serem incipientes os estudos de clima em cidades de pequeno e médio porte, o arcabouço teórico-metodológico e conceitual para elaboração dos mesmos é limitado. Monteiro (1990) coloca que qualquer análise introdutória para estudo do clima urbano requer acurada observação da topologia do sítio e da morfologia urbana, assim como das interações entre eles. Em se tratando de cidades de pequeno e médio porte, Mendonça (2000, 2003a) atribui ao sítio urbano papel de destaque, recomendando seu conhecimento detalhado. Afinal, quanto menor a cidade maior será o papel do sítio e da circulação atmosférica regional no clima.

Por sítio urbano entende-se o espaço físico sobre o qual a cidade se ergue e que traduz as características do ambiente ao nível da superfície terrestre (JARDIM e FERREIRA, 2005; ROSSATO, 2010).

Já o clima urbano é um sistema que engloba o clima de uma dada porção do espaço, com suas características e feições próprias, e o fenômeno da urbanização sobre ele implantado (MONTEIRO, 2003).

Com base nisso, o presente trabalho visa contribuir com o debate sobre o papel do sítio e da altimetria sobre a variação termohigrométrica e definição do caráter climático das cidades na Zona da Mata Mineira. Para tanto, foram realizados experimentos de campos em cinco municípios distintos, situados em altitudes e posições geográficas distintas, ao longo 
do perfil Ponte Nova-Ubá sob condições de tempo anticiclonais característica de situações sazonais de verão (Dias 27 e 28 de janeiro e 2 e 3 de fevereiro de 2011).

\section{Área de Estudo}

A Zona da Mata Mineira (Figura 1) encontra-se sob domínio da unidade geomorfológica dos planaltos cristalinos rebaixados, também denominados de Mar de Morros (AB'SABER, 2003, p. 16), que sofreu arqueamentos que deram origem a fraturas e falhas responsáveis pelo rebaixamento dos planaltos (Golfão de Ubá) e pelo soerguimento do Maciço do Caparaó, bem como das Serras de São Geraldo, Brigadeiro e Muriaé.

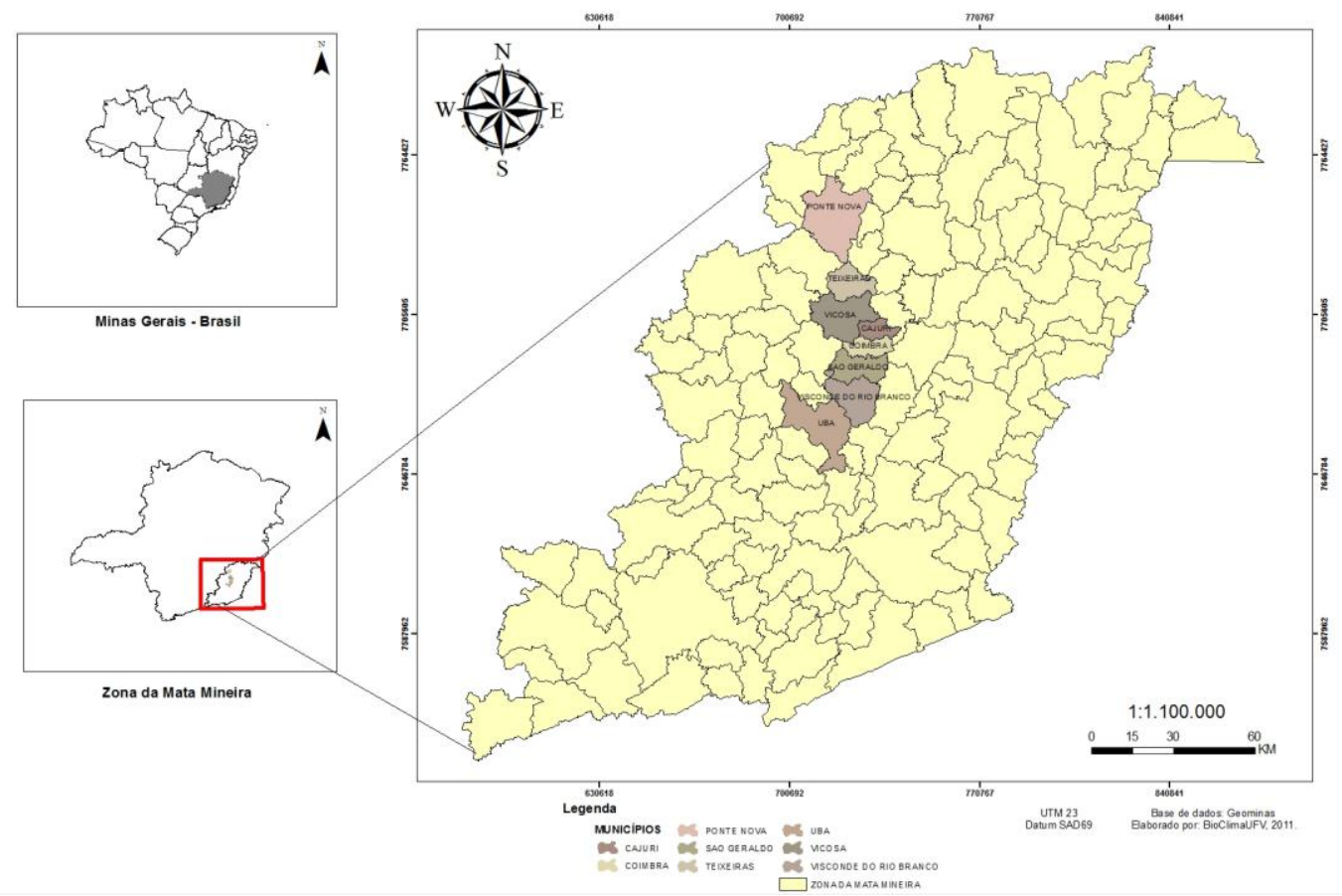

Figura 1: Localização geográfica da Zona da Mata Mineira e dos municípios da área de estudo.

A principal característica da paisagem é a presença de um relevo fortemente ondulado e montanhoso, com morros em meia-laranja, resultantes da dissecação fluvial (NUNES, et. al., 2001), onde se destacam as bacias dos rios Paraíba do Sul e Doce, que influenciaram decisivamente no modo de ocupação da área, que se guiou pela orientação dos vales fluviais. O nome da região de Zona da Mata Mineira foi atribuído em virtude da fisionomia da vegetação natural, hoje praticamente inexistente em conseqüência do processo de ocupação, marcado, sobretudo no seu início, pela forte atividade agrária que propiciou uma devastação da mata primária de maneira generalizada (VALVERDE, 1958; MARCHI et. al., 2005).

Ponte Nova, Teixeiras e Viçosa localizam-se na bacia do Rio Doce. Já Visconde do Rio Branco e Ubá situam-se na bacia do Rio Paraíba do Sul. O 
interflúvio das duas bacias na área de estudo é a escarpa de São Geraldo ${ }^{1}$, que tem aproximadamente 667 metros de altitude e proporciona um desnível altimétrico entre o planalto de Viçosa e a planície, na qual estão localizados Visconde do Rio branco e Ubá de cerca de 300 metros.

Dessa forma, temos a sotavento da escarpa de São Geraldo os municípios de Ponte Nova, Teixeiras e Viçosa, e a barlavento os municípios de Visconde do Rio Branco e Ubá. Tanto o município de Visconde do Rio Branco, quanto o de Ubá encontram-se envolvidos pelo "Golfão de Ubá" (Figura 2), cuja origem tectônica (ANDRADE, 1961), promoveu o desenvolvimento de uma reentrância no complexo da Mantiqueira, dandoIhe feição semelhante a uma ferradura quando observado do alto da Serra de São Geraldo.

Em relação à rede urbana da Zona da Mata Mineira, as cidades em questão podem ser classificadas de pequeno, exceto Ubá, se considerar critérios quantitativos ${ }^{2}$, porém ao se observar o desempenho das funções do lugar central, Viçosa e Ubá podem ser consideradas cidades de médio porte, enquanto as demais de pequeno porte. $\mathrm{O}$ quadro 1 a seguir apresenta algumas informações gerais, que nos auxilia a dimensioná-los.

Quadro 1 - Dados relativos aos municípios em estudo.

\begin{tabular}{|l|c|c|c|c|c|}
\hline Cidades & $\begin{array}{c}\text { Altitude } \\
\text { média dos } \\
\text { pontos de } \\
\text { coleta }\end{array}$ & $\begin{array}{c}\text { Distância das } \\
\text { cidades a } \\
\text { partir de } \\
\text { Ponte Nova }\end{array}$ & $\begin{array}{c}\text { Área do } \\
\text { município } \\
(\mathrm{Km})\end{array}$ & $\begin{array}{c}\text { População do } \\
\text { município }\end{array}$ & $\begin{array}{c}\text { População } \\
\text { urbana }\end{array}$ \\
\hline Ponte Nova & $481 \mathrm{~m}$ & - & 470,64 & 57.361 & $\begin{array}{c}51.152 \\
(89,18 \%)\end{array}$ \\
\hline Teixeiras & $657 \mathrm{~m}$ & $31 \mathrm{Km}$ & 166,7 & 11.346 & $\begin{array}{c}7.605 \\
(67,03 \%)\end{array}$ \\
\hline Viçosa & $642 \mathrm{~m}$ & $45 \mathrm{Km}$ & 299,42 & 72.244 & $\begin{array}{c}67.337 \\
(93,21 \%)\end{array}$ \\
\hline $\begin{array}{l}\text { Visconde do Rio } \\
\text { Branco }\end{array}$ & $345 \mathrm{~m}$ & $90 \mathrm{Km}$ & 243,35 & 37.952 & $\begin{array}{c}31.397 \\
(82,73 \%)\end{array}$ \\
\hline Ubá & $390 \mathrm{~m}$ & $110 \mathrm{Km}$ & 407,45 & 101.466 & $\begin{array}{c}97.599 \\
(96,19 \%)\end{array}$ \\
\hline
\end{tabular}

Fonte: IBGE (2010).

Em relação à dinâmica climática, a área de estudo de acordo com Abreu (1997) se encontra em uma faixa de transição, caracterizada por um regime de duas estações bem definidas: seca (inverno), na qual atuam a Frente Polar Atlântica (FPA) e o anticiclone subtropical do Atlântico Sul; e chuvosa (verão), na qual predominam os sistemas convectivos associados ao

${ }^{1}$ A Escarpa de São Geraldo pertence ao complexo da Mantiqueira, que localiza-se na borda do cráton de São Francisco, de rochas predominantemente ortognaisses bandeadas. Sua disposição é preferencialmente no sentido NE - SW, com extensão de aproximadamente $750 \mathrm{Km}$, constituindo a mais importante formação orográfica do chamado Brasil Sudeste (ANDRADE, 1961; ROCHA, 2009).

2 as cidades pequenas a partir de um contingente populacional de até 100 mil habitantes; as cidades médias, entre 100 mil e 500 mil habitantes; e as cidades grandes, com número superior a 500 mil habitantes. 
aquecimento continental e a zona de convergência do Atlântico Sul (FERREIRA; NERY, 2002).

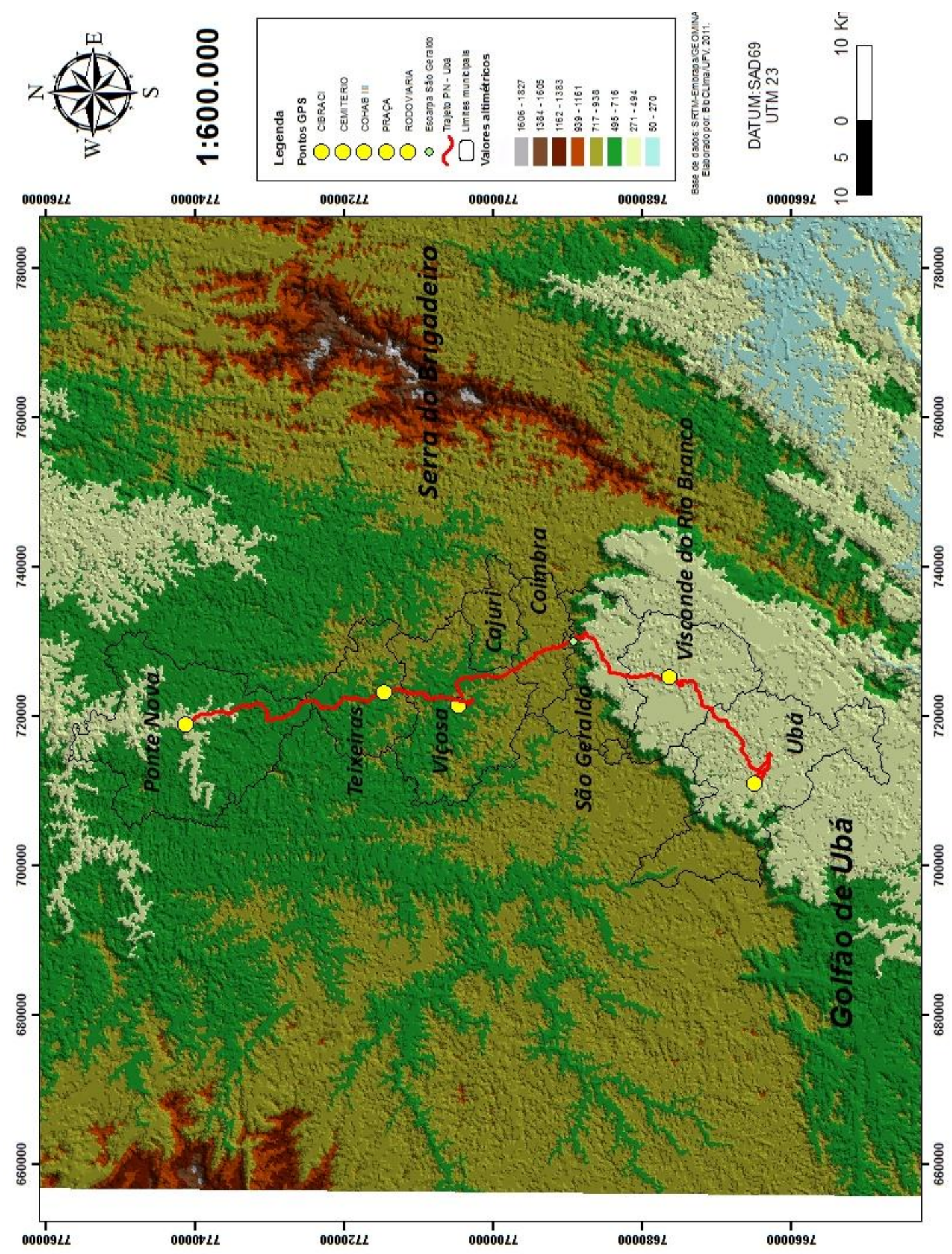


Figura 2: Mapa altimétrico da área de estudo, compreendendo os municípios de Ponte Nova, Teixeiras, Viçosa, Visconde do Rio Branco e Ubá, que fazem parte do Transeto Ponte Nova-Ubá.

\section{Material e Métodos}

Para alcançar o objetivo colocado, o presente trabalho adotou a proposta de transetos fixos (SEZERINO e MONTEIRO, 1990; BRANDÃO e TARIFA, 1995, BRANDÃO, 1992, 1996 e 2001; FIALHO, 2002 e 2010; ASSIS, 2010), com 5 pontos de coleta, ao longo dos municípios de Ponte Nova, Teixeiras, Viçosa, Visconde do Rio Branco e Ubá. Para cada ponto de mensuração (escala topoclimática), o valor foi obtido, a partir da média da leitura de três medidas ao longo da vertente da encosta, na escala microclimática.

A escolha por 3 pontos de medida em cada cidade amostrada, decorre do fato das mesmas se localizarem em grande parte nos fundos dos vales, espraiando-se pelas vertentes. Em razão disso, optou-se em mesurar no fundo do vale, a média encosta e o topo das colinas, a fim de registrar não apenas a influência microclimática, mas topoclimática.

Os parâmetros climáticos registrados nos dias 26 e 27 de janeiro e 2 e 3 de fevereiro de 2011, foram temperatura do ar e umidade relativa do ar, nos horários de 9:00h, 12:00h, 15:00h, 18:00h e 21:00h.

Para obtenção dos dados foram utilizados 5 Termohigrômetros (TH) digital modelo MTH - 1380, todos aferidos previamente na Estação Meteorológica da Universidade Federal de Viçosa (Figura 3).

Em relação às condições sinóticas, as mesmas foram realizadas, com base nas cartas sinóticas provenientes do Centro de Previsão de Tempo e Estudos Climáticos (CPTEC - www.cptec.inpe.br), da Diretoria de Hidrologia e Navegação da Marinha (DHN - https://www.mar.mil.br/dhn), bem como o Sistema de Meteorologia e Recursos Hídricos de Minas Gerais (SIMGE www.simge.mg.gov.br).

Os dados registrados em campo foram corrigidos, a partir da elaboração do gráfico de dispersão e da equação da reta de correlação linear de cada termohigrômetro, desenvolvidos no programa Microsoft Oficce Excel 2007.

Nas equações que se seguem (Quadro 2) " $Y_{(t)}$ ", " $Y_{(u)}$ "e " $x$ " representam, respectivamente, os valores de temperatura aferido, umidade aferido e o dado registrado em campo. Já a equação do " $\mathrm{R}^{2}$ " indica a precisão de cada termohigrômetro digital em relação aos termômetros de bulbo seco e bulbo úmido da Estação Meteorológica de Viçosa. Quanto mais próximo de 1,0 valor de $\mathrm{R}^{2}$ mais preciso é o equipamento.

Quadro 2 - Equações de correlação linear, obtidas após aferição dos termohigrômetros em relação a Estação Meteorológica de Viçosa.

\begin{tabular}{|c|c|c|}
\hline Termohigrômetro & Equação Y (t) & Equação Y (u) \\
\hline TH-01 & $\begin{array}{l}Y_{(t)}=1,0922 x-2,0403 \cdot R^{2}=0 \\
9213\end{array}$ & $Y_{(U)}=1,0993 x-2,0532 . R^{2}=0,9038$ \\
\hline TH-02 & $Y_{(t)}=1,0997 x-2,0302 \cdot R^{2}=09816$ & $Y_{(U)}=1,0601 x-053 \cdot R^{2}=0,8866$ \\
\hline TH-03 & $Y_{(t)}=1,123 x-2,7684 . R^{2}=0,9772$ & $Y_{(U)}=1,0991 x-3,0985 . R^{2}=0,8708$ \\
\hline TH-04 & $Y_{(t)}=1,0619 x-0,9848 \cdot R^{2}=0,9628$ & $Y_{(U)}=1,068 x-2,2033 . R^{2}=0,8795$ \\
\hline TH-05 & $\begin{array}{l}Y_{(t)}=0,9742 x+1,2859 . R^{2}= \\
0,9605\end{array}$ & $Y_{(U)}=1,0837 x-5,08792$ \\
\hline
\end{tabular}


Após a aferição dos dados foram elaborados os transetos de temperatura e umidade relativa do ar, utilizando-se do software Surfer for Windows ${ }^{\circledR}$ v. 10, para melhor representar o comportamento desses parâmetros climatológicos ao longo dos horários de mensuração, bem como a variação dos mesmos ao longo do perfil topográfico da área de estudo.

Dentro do programa Surfer for Windows ${ }^{\circledR}$ v. 10, utilizou-se o interpolador Krigagem Ordinária. Na elaboração dos transetos de temperatura e umidade do ar foram estabelecidas escalas de cores para os valores de temperatura. As cores frias foram associadas a temperaturas mais baixas e as cores quentes a temperaturas mais altas. No transeto de umidade ar os valores de umidade foram representados utilizando as tonalidades de da cor azul para representar os maiores valores de umidade, decrescendo até a cor amarelo claro, com valores mais baixos, passando pelos valores intermediários, representados pela cor verde.

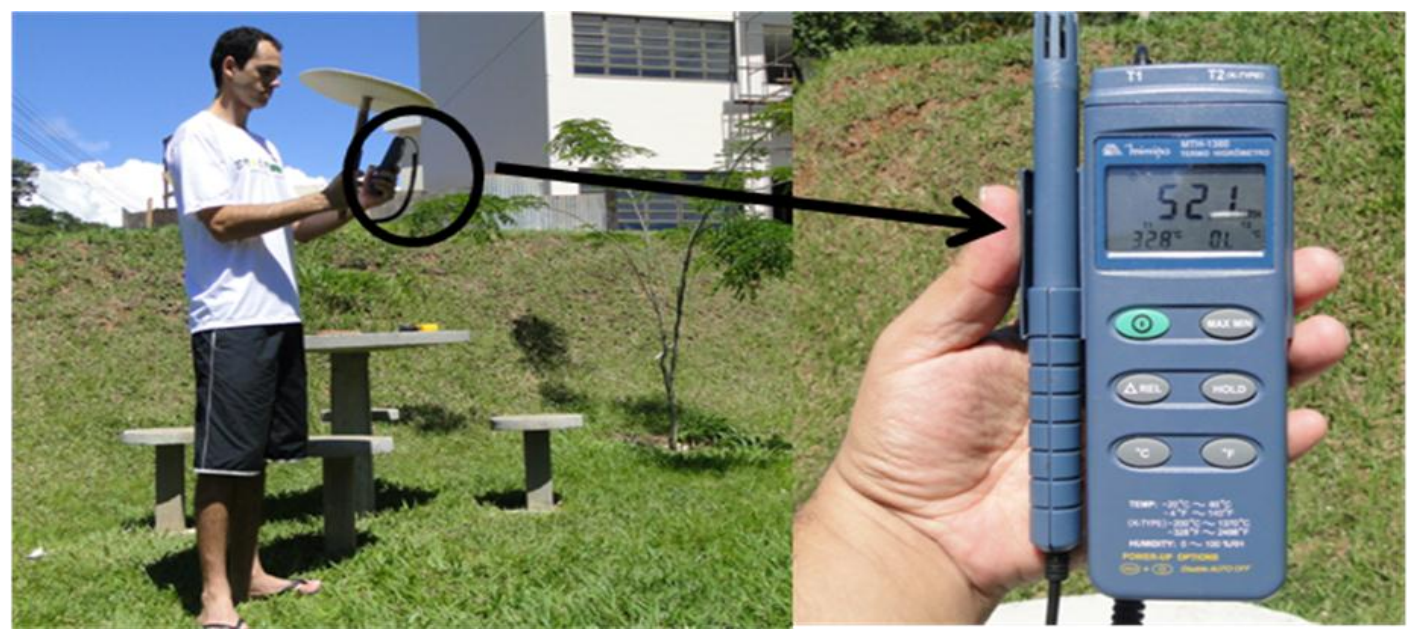

Figura 3: Termohigrômetros (TH) digital modelo MTH - 1380

Em relação aos dados representados nos transetos, estes indicam a variação encontrada ao longo do perfil em cada horário de registro. Dessa forma, o zero indica o menor valor registrado entre as cinco cidades para aquele horário de medição, e os demais valores representam a diferença positiva encontrada. Os Quadros 3 e 4 ilustram os procedimentos descrito nesse parágrafo.

Quadro 3 - Diferença de temperatura do ar $\left({ }^{\circ} \mathrm{C}\right)$ verificada para cada horário de medição no dia 27 de janeiro de 2011.

\begin{tabular}{|c|c|c|c|c|c|c|}
\hline Horário & Ponte Nova & Teixeiras & Viçosa & Visc. Rio Branco & Ubá & Zero igual a: \\
\hline $9: 00$ & 1.8 & 1.7 & 0 & 5.3 & 8.7 & 25.5 \\
\hline $12: 00$ & 1.9 & 1 & 0 & 5.7 & 8.8 & 29.4 \\
\hline $15: 00$ & 2.9 & 2.7 & 0 & 5.8 & 10.2 & 30.8 \\
\hline $18: 00$ & 0.8 & 1.4 & 0 & 1.4 & 5.8 & 31.6 \\
\hline $21: 00$ & 2.8 & 0 & 3.3 & 2.8 & 8.8 & 25.4 \\
\hline
\end{tabular}


Quadro 4 - Diferença de umidade relativa do ar (U.R.\%) verificada para cada horário de medição no dia 27 de janeiro de 2011.

\begin{tabular}{|c|c|c|c|c|c|c|}
\hline Horário & Ponte Nova & Teixeiras & Viçosa & Visc. Rio Branco & Ubá & Zero igual a: \\
\hline $9: 00$ & 20.5 & 21.7 & 23.9 & 12.3 & 0 & 52.7 \\
\hline $12: 00$ & 14.8 & 56.6 & 27.4 & 13.1 & 0 & 39.5 \\
\hline $15: 00$ & 10.3 & 19.3 & 24.6 & 9.5 & 0 & 36.6 \\
\hline $18: 00$ & 3.9 & 8.6 & 10 & 17.4 & 0 & 41.9 \\
\hline $21: 00$ & 20.4 & 32.4 & 19.9 & 34.6 & 0 & 45.6 \\
\hline
\end{tabular}

\section{Resultados e Discussões}

Com base na colocação de Geiger (1961), as manchas urbanas, bem como as áreas desocupadas nos municípios de Ubá, Visconde do Rio Branco, Viçosa, Teixeiras e Ponte Nova apresentariam uma alteração de seu clima inerente à condição do seu sítio convergente.

Porém, com o crescimento dos distritos sedes de alguns municípios, como Ubá, Viçosa e Ponte Nova, que apresentam uma expansão da mancha urbana ao longo de vales e agora se espraiando pelas vertentes adjacentes surgem uma questão: a área urbana dos municípios compreendidos desenvolve a capacidade de gerar uma diferenciação entre o ambiente da cidade e o do seu entorno rural?

Apesar da identificação da mudança no clima ao nível da cidade causada por uma transformação urbana/social seja muito difícil de ser identificado, conforme observa Landsberg (2006, p. 25), Fialho (2009) ao investigar a dinâmica do campo térmico de Viçosa, observou a influência das brisas de montanhas descaracterizando a ilha de calor, ocasionando uma homogeneização ao longo do percurso de mensuração, bem como da topografia, principalmente no período da tarde, mas não identificou um clima urbano estruturado, conforme sugere os trabalhos de Tangará da Serra e Barra do Bugres (ZAMPARONI, 1995); Teodoro Sampaio (VIANA e AMORIM, 2008); Nova Palma (ROSSATO, 2010), Guararapes (MINAKI e AMORIM, 2005), Birigui (AMORIM, 2005) e Barbosa Ferraz (DONATO, 2009).

Nesse contexto, urge a necessidade de compreender melhor a influência do sítio sobre o clima das áreas urbanas dos municípios envolvidos nesse estudo, como também confrontar as impressões humanas, observadas ao longo da preparação dos experimentos de campo.

O enquadramento sinótico dos dias de mensuração, mostra que o tipo de tempo atuante sobre a Zona da Mata Mineira, amanheceu sob o efeito de anticiclone semi-fixo do atlântico sul - ASAS (Figuras 4 e 5), com intensidade de $1016 \mathrm{hpa}$, que favorecia a drenagem de ventos de leste sobre o litoral, que transportava umidade do oceano para o interior do continente, gerando ao longo dos dias uma oscilação da nebulosidade.

As manhãs registravam uma cobertura variável entre $3 / 8$ e $2 / 8$, com nuvens stratus, por causa da circulação anticiclônica, que ao diminuir de intensidade no período da tarde, produzia um aumento da radiação, decorrente da redução da nebulosidade.

A consequência disso é que as temperaturas máximas ao longo dos 4 dias de experimento não ocorreram apenas às 15:00 horas, momento em que o 
horizonte apresentava um céu de brigadeiro, ou seja, com ausência de nuvens. Muito embora, a diferença máxima identificada ao longo dos 4 dias de experimento fora observada às 15:00 horas entre Teixeiras e Ubá, com uma intensidade de $10,2^{\circ} \mathrm{C}$, no dia 27 de janeiro.

Nos dias 26 de janeiro e 2 de fevereiro, o horário da temperatura máxima, bem como a diferença máxima entre os pontos de medida foram às 12:00 horas e às 18:00, respectivamente, fortemente influenciada pela variabilidade da cobertura do céu.

Ao longo do perfil topoclimático do transeto Ponte Nova-Ubá foram monitorados 5 municípios (Ponte Nova, Teixeiras, Viçosa, Visconde do Rio Branco e Ubá). A variação têmporo-espacial da temperatura do ar individualiza dois núcleos de maior aquecimento, um engloba o Golfão de Ubá, com os municípios de Visconde do Rio Branco e Ubá e o outro em Ponte Nova, cuja continuidade é interrompida pela presença dos municípios de Teixeiras e Viçosa, conforme pode ser visualizado nas Figuras 6,7, e 8.

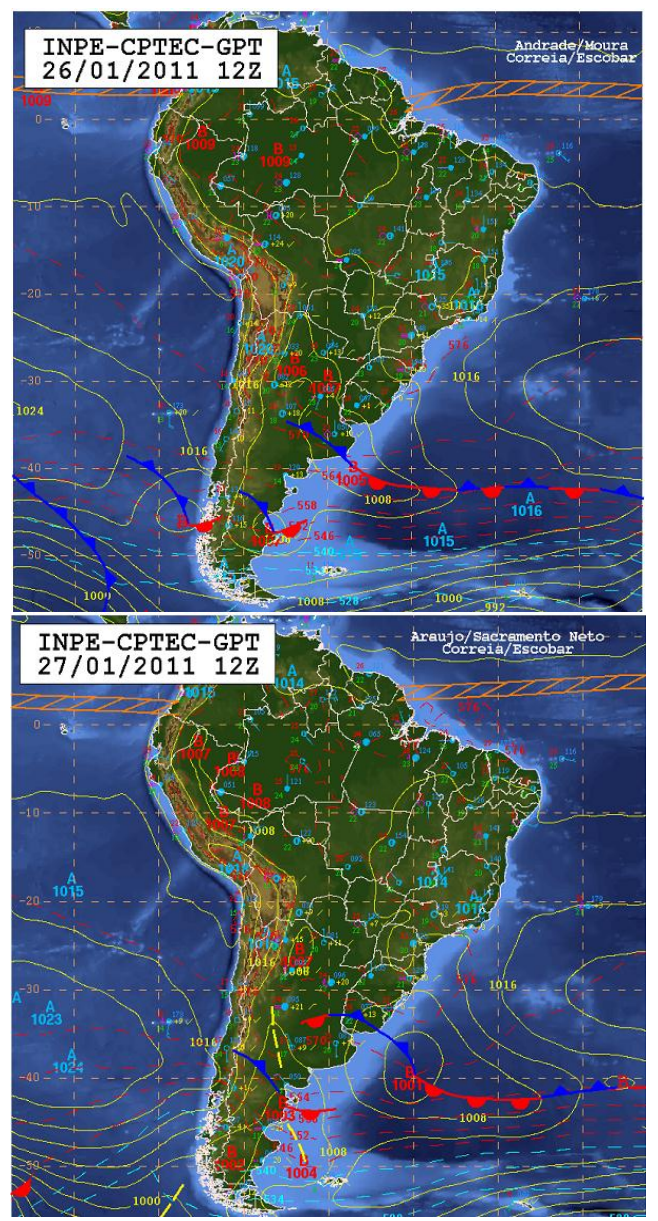

Figura 4 - Cartas sinóticas das 12 horas dos dias 26 e 27 de janeiro de 2011. 


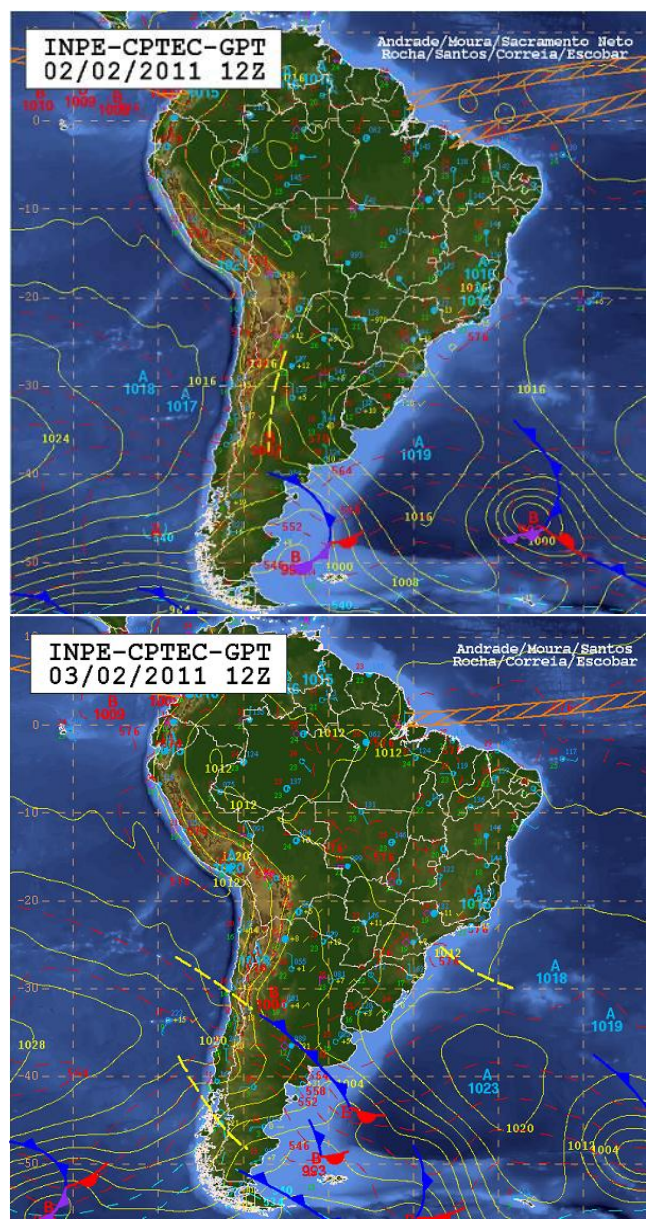

Figura 5 - Cartas sinóticas das 12 horas dos dias 02 e 03 de fevereiro de 2011. Fonte: Centro de Previsão do tempo e estudos climáticos (CPTEC-INPE). Disponível em: http://tempo.cptec.inpe.br. Acesso em 10 dez. 2011

Nos dias 26 e 27 de janeiro (Figura 6) Ubá registrou maiores valores de temperatura do ar em relação a Visconde do Rio Branco em todos os horários de medidas. Já nos dias 2 e 3 de fevereiro (Figura 7) foi verificado o oposto, onde Visconde do Rio Branco apresentou maiores valores de temperatura do que Ubá, exceto às 21:00 horas.

De acordo com conversas preliminares com estudantes da UFV, que residem no Golfão de Ubá e moradores de Viçosa, a fim de colher informações prévias para definição de pontos de coleta, os dois grupos declararam Ubá ser a localidade mais quente, desconsiderando os demais municípios que fazem parte do Golfão.

Porém, como o sítio convergente abarca inúmeros municípios, a princípio questionamos essa primícia. E de fato, quando se observa os dados nos dias 2 e 3 de fevereiro Visconde do Rio Branco registra as maiores temperaturas, mas às 21:00 horas Ubá sempre apresenta registros térmicos superiores, tendo a diferença máxima identificada entre ambas, no dia 27 de janeiro, com $6,0^{\circ} \mathrm{C}$. Esse fato de Ubá ser mais quente às 
21:00 horas, nos coloca uma questão. Será que Ubá já apresenta condições de desenvolver uma ilha de calor?

Em relação às cidades de Teixeiras e Viçosa, situadas no planalto e em cotas altimétricas superiores as demais, essas registraram as menores temperaturas ao longo do perfil nos quatro dias de medições, principalmente, Viçosa. Analisando de forma comparada Teixeiras e Viçosa, observa-se que em praticamente todos os dias de registro a primeira cidade obteve temperaturas superiores à segunda, sobretudo durante a tarde, entre 12:00 e 15:00 horas.

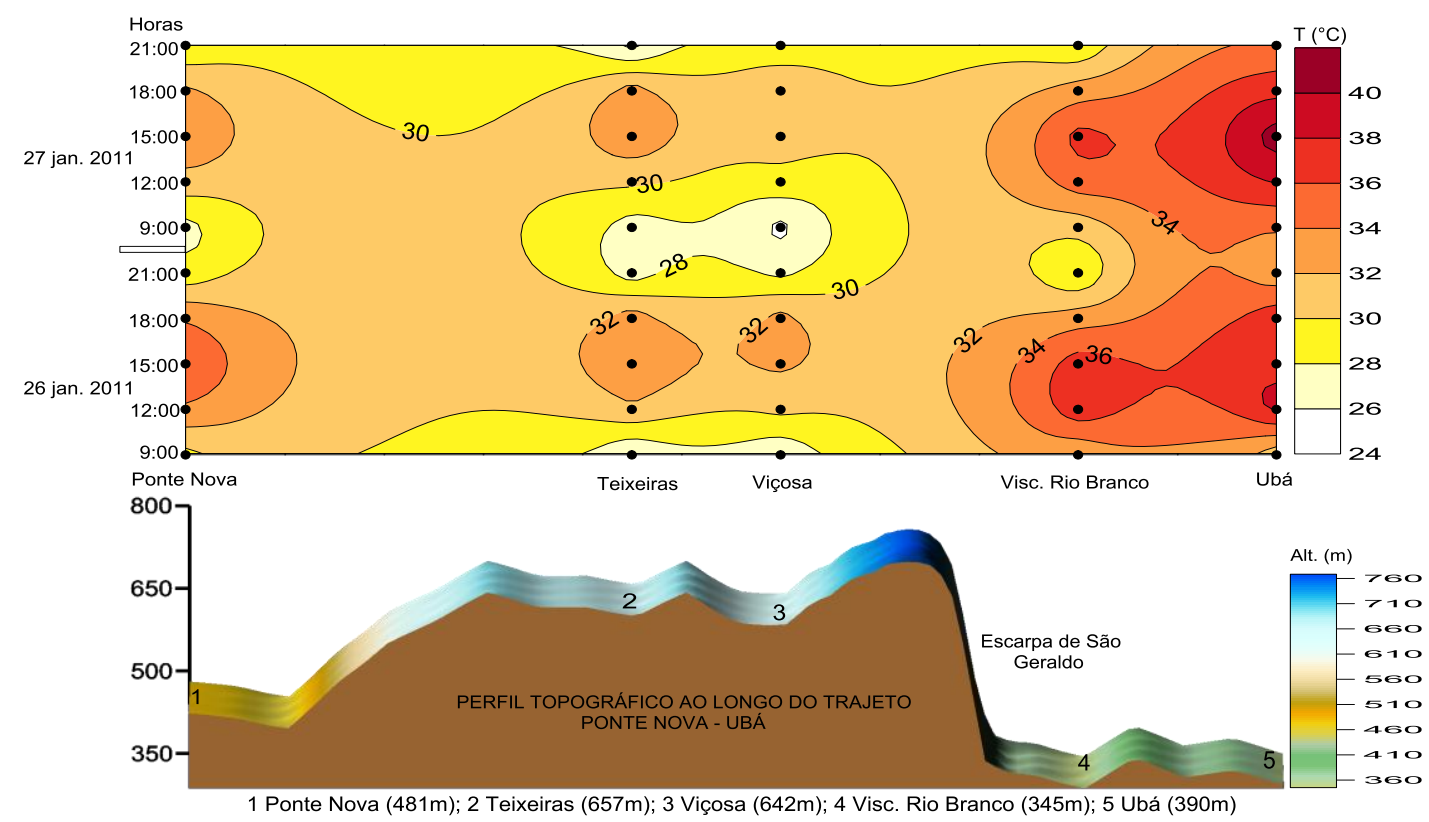

Figura 6 - Variação da Temperatura do ar ao longo do transeto Ponte Nova-Ubá entre os dias 26 e 27 de janeiro de 2011.

Nos dias 2 e 3 de fevereiro, nos horários de 15:00 e 18:00 horas respectivamente, Teixeiras se destacou, apresentando temperaturas consideravelmente mais elevadas do que Viçosa, semelhantes às de Ponte Nova.

Esses resultados obtidos entre Teixeiras e Viçosa, inicialmente, podem despertar uma suspeita, uma vez que Viçosa apresenta um contingente populacional 7 vezes superior a Teixeiras, o que denuncia uma mancha urbana maior. Porém, quando ao comparar as duas cidades, identificam-se algumas diferenças entre ambas, quanto às formas dos vales e no desnível altimétrica ente o topo das colinas e o fundo dos vales, superior em Viçosa em relação à Teixieras.

Isto por sua vez, implica em duas coisas importantes. Primeiro, o volume de ar a ser aquecido é maior em Viçosa, o que explica o fato de Viçosa quase sempre ser mais fria nos primeiros horários da manhã. Tal fato é corroborado, quando em entrevistas com alguns moradores do bairro do João Braz, em Viçosa, relatam que até o final da década de 1990, o mesmo 
era conhecido como buraco frio, mas hoje não mais, em virtude do avanço da mancha urbana da cidade.

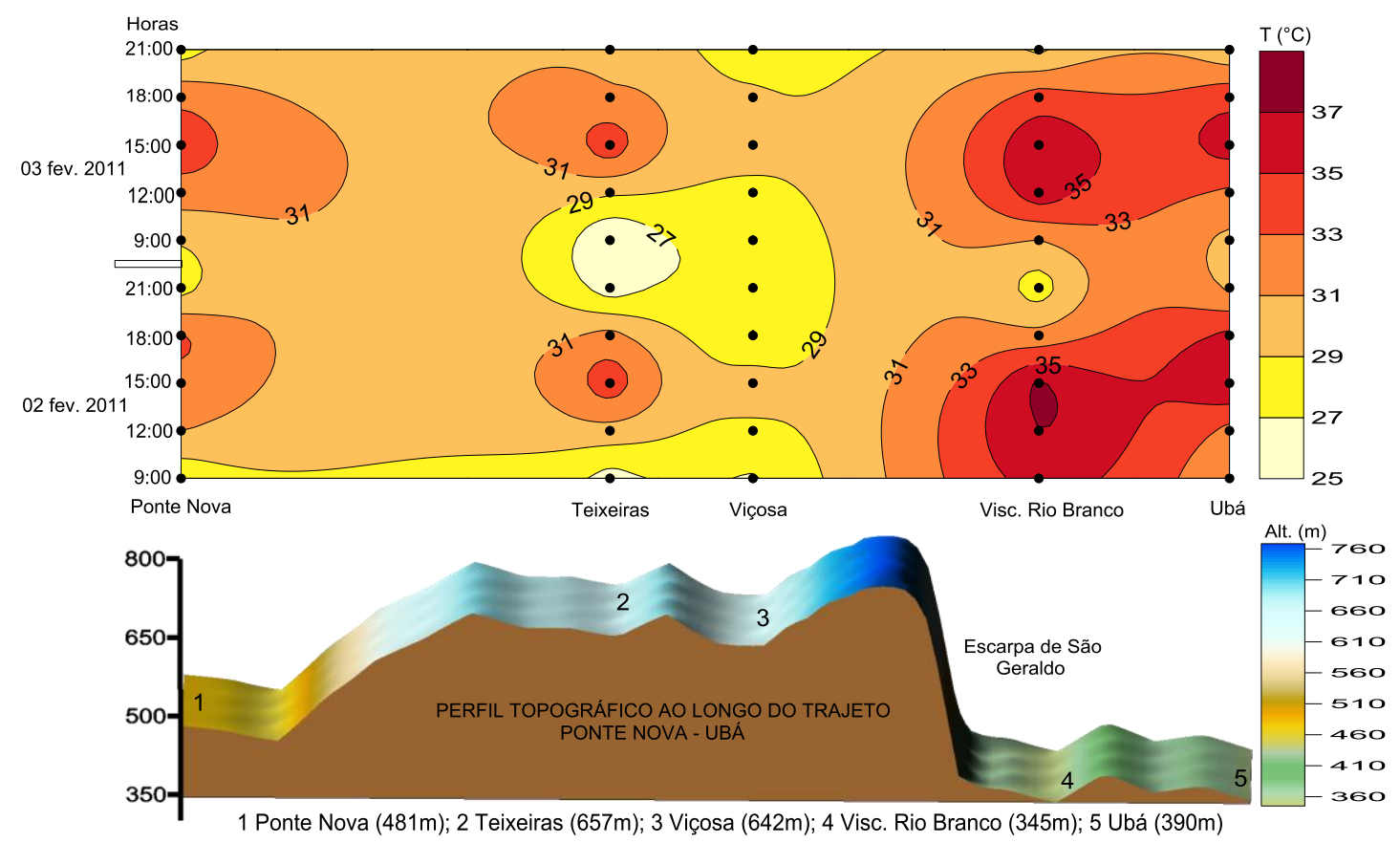

Figura 7 - Variação da Temperatura do ar ao longo do transeto Ponte Nova-Ubá entre os dias 2 e 3 de fevereiro de 2011.

Segundo, como a área adjacente tem como uso predominante da terra, a pastagem e o de terra batida, associada a uma área urbana menor, Teixeiras registra uma grande taxa de aquecimento, que produz diferenças de até $5,1^{\circ} \mathrm{C}$ às $15: 00$ horas no dia 3 de fevereiro de 2011 .

Já Ponte Nova obteve temperaturas intermediárias, ou seja, superiores às de Teixeiras e Viçosa, em praticamente todos os horários, e inferiores às de Visconde do Rio Branco e Ubá. A partir do transeto (Figura 8) é possível notar que nas medições de fevereiro Ponte Nova apresentou ser mais quente em relação às medições de janeiro.

Em termos qualitativos, o perfil térmico evidenciado ao longo do percurso, assemelha-se aos resultados obtidos por Mora (2009), que ao pesquisar as características climáticas na Serra da Estela em Portugal, constatou menores valores nos planaltos e maiores valores nos fundos de vale, bem como observou que os fundos de vale situados a maior altitude registraram temperaturas inferiores às dos vales a menor altitude.

O fator altitude, aliado às características topográficas do percurso que se estende de Ponte Nova a Ubá, apresenta ser significativo na compreensão do campo térmico da área em estudo.

As duas cidades localizadas a menor altitude, na planície, apresentaram as maiores temperaturas, e as duas cidades localizadas a maior altitude, no planalto, apresentaram menores temperaturas. Já a cidade localizada a 
uma altitude intermediária, também apresentou temperaturas intermediárias.

Sant'anna Neto (2005, p. 47) ao discorrer sobre os dez fatores ou processos que explicam a diversidade climática da região sudeste do Brasil afirma que: "Nenhuma outra região brasileira apresenta influência tão nítida e marcante da altimetria e disposição do relevo nas configurações dos climas regionais".

Nesse sentido, Fritzsons et. al. (2008) dizem que nas regiões tropicais e subtropicais a relação direta da temperatura com a altitude é importante na definição dos climas, uma vez que diferenças altimétricas de algumas centenas de metros estimulam consideráveis modificações climáticas.

No entanto, as diferenças de temperatura registradas entre as cidades localizadas no Golfão de Ubá e as cidades acima da Serra de São Geraldo, não podem ser justificadas apenas pelo fator altitude, uma vez que a correlação entre altitude e temperatura média e diária, não forneceu uma equação linear da reta com $R^{2}$ negativo, o que demonstra a falta $e$ correlação.

Baseado na relação temperatura/altitude referida no parágrafo anterior, o desnível altimétrico de aproximadamente 300 metros entre o planalto de Viçosa e Planície de Ubá seria responsável por uma variação de cerca de 1,8 a $3,0{ }^{\circ} \mathrm{C}$ de temperatura entre essas duas localidades. No entanto, os valores registrados em campo não são condizentes a tal analogia, como mostra o transeto de temperatura do ar (Figura 8) e o quadro 3.

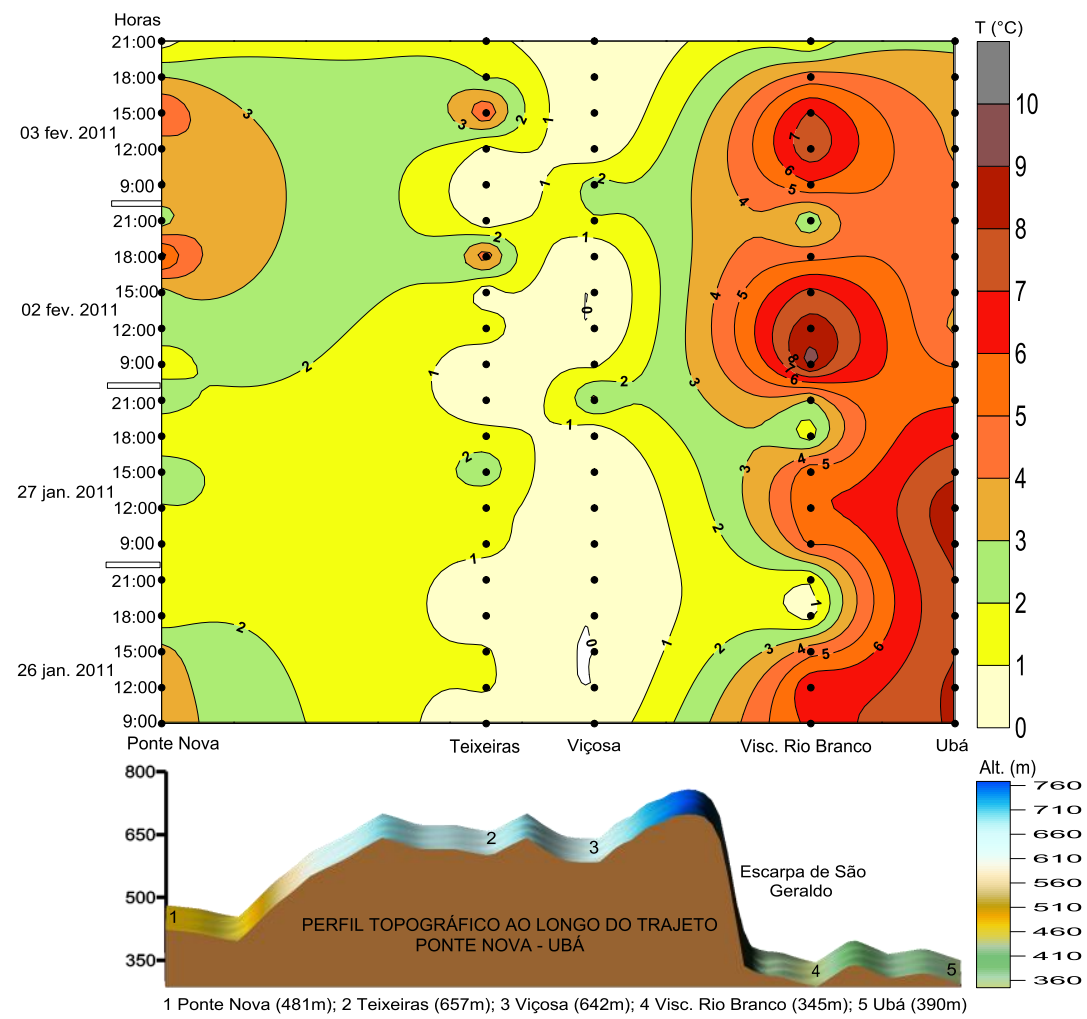

Figura 8. Variação da diferença de Temperatura do ar ao longo do Perfil Ponte Nova-Ubá nos dias 26 e 27 de Janeiro e 2 e 3 de Fevereiro de 2011. 
Em relação à umidade relativa do ar (Figuras 9, 10 e 11) verifica-se que as áreas de maior temperatura do ar, em grande parte, foram aquelas que registraram menores valores de umidade. Porém, os dados de temperatura e umidade relativa do ar, no percurso analisado, não apresentaram relações diretamente inversas, conforme Falcão et. al. (2010) identificou em estudo realizado no Pico da Bandeira, Alto Caparaó, ao analisar a variação da umidade relativa do ar em um perfil topoclimático,uma significativa relação entre altitude e umidade relativa do ar, com a presença ou ausência de cobertura vegetal do solo.

Nos registros do mês de janeiro a umidade do ar (Figura 9) em Visconde do Rio Branco foi superior a de Ubá, exceto nas duas primeiras horas de medições do dia 26. Nas medições de fevereiro, embora Ubá tenha apresentado temperaturas inferiores às de Visconde do Rio Branco, a umidade do ar nessa cidade foi superior à daquela.

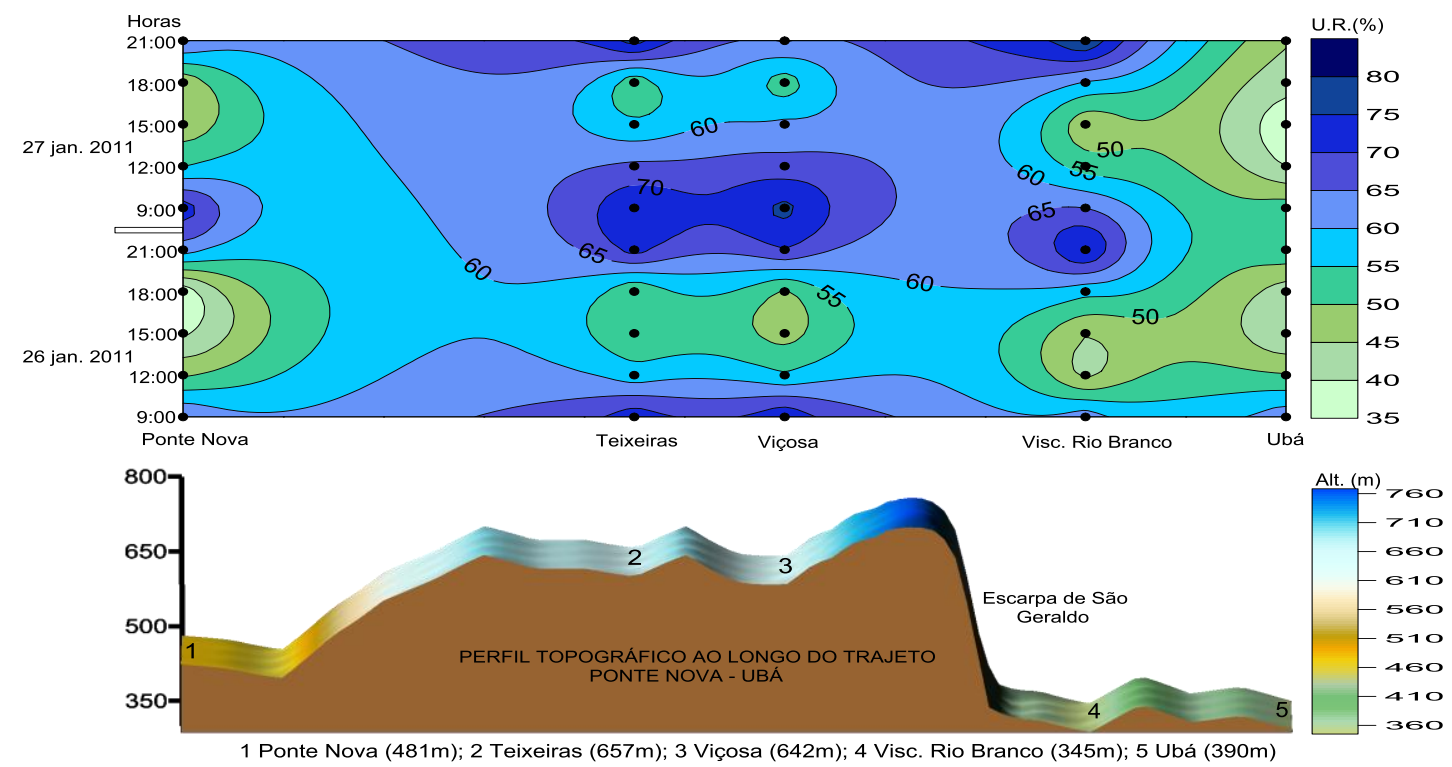

Figura 9 - Variação da Umidade relativa do ar ao longo do transeto Ponte Nova-Ubá entre os dias 26 e 27 de janeiro de 2011. 


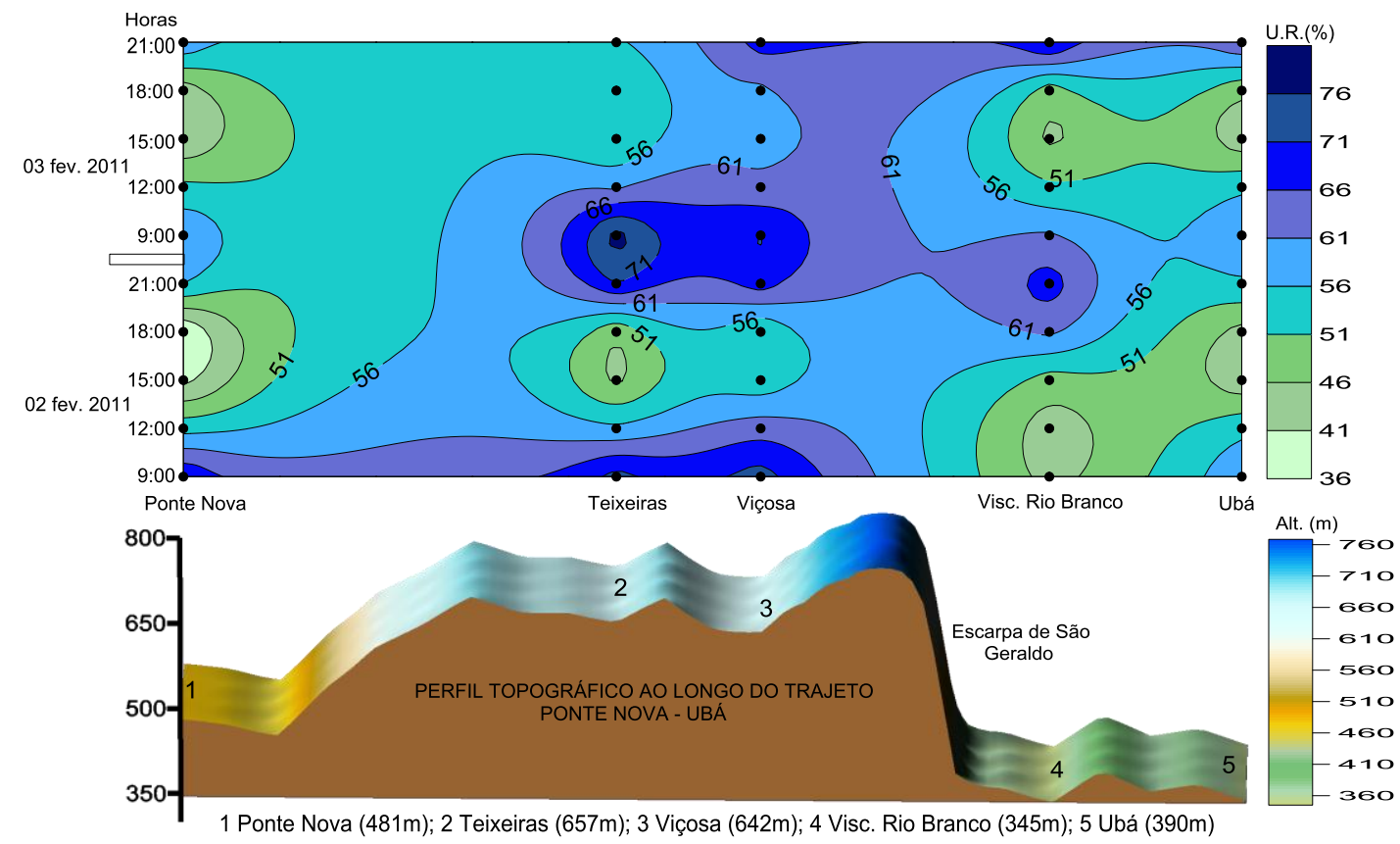

Figura 10 - Variação da Umidade relativa do ar ao longo do transeto Ponte NovaUbá entre os dias 2 e 3 de fevereiro de 2011.

Em Teixeiras e Viçosa, cidades que obtiveram temperaturas menores que as demais se constatou os maiores valores de umidade relativa do ar, nos quatro trabalhos de campo (Figura 11). Teixeiras e Viçosa demonstraram registros de umidade semelhantes, sendo que apenas no dia 27 de janeiro Teixieras se destacou em relação à Viçosa, com uma diferença de 32,5\%, às 12:00 horas.

De uma maneira geral, os resultados demonstram que para as condições de predomínio do Sistema Tropical Atlântico se coaduna com os resultados alcançados por Galvani et. al. (2009) no perfil topoclimático realizado, no Parque Estadual de Intervales (Estado de São Paulo) entre as cotas altimétrica de 150 a 950 m não encontraram uma relação direta entre a altitude e a variação da umidade relativa do ar.

Tais autores constatam, que o controle da umidade relativa do ar é mais ativo em relação ao nível escalar microclimático (uso do solo, cobertura vegetal e estrutura do dossel da vegetação) do que na escala topoclimática. Porém, para o perfil Ponte Nova-Ubá, ainda não é possível afirmar, sendo necessário aprofundar e intensificar a investigação.

Ponte Nova veio a ser a cidade com menor umidade relativa do ar, conforme mostra o transeto, onde há predominância da cor amarelo claro no dia 26 de janeiro e nos dias 2 e 3 de fevereiro de 2011. Apenas no dia 27 de janeiro Ponte Nova evidenciou valores de umidade intermediários em relação às cidades de planalto e às cidades de planície, assim como ocorrido com a temperatura. 


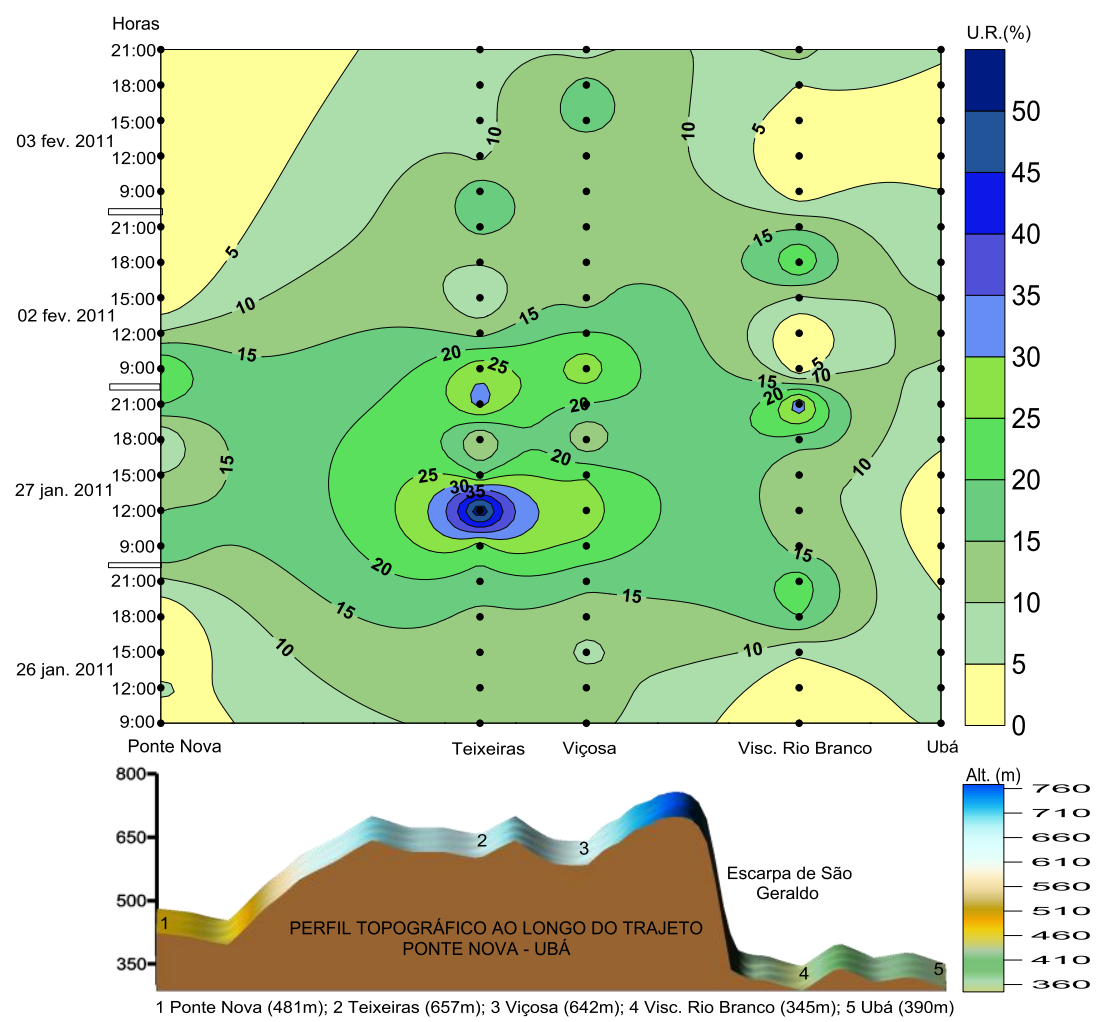

Figura 11. Variação da umidade relativa do ar ao longo do perfil Ponte Nova-Ubá nos dias 26 e 27 de janeiro e 2 e 3 de fevereiro de 20011 .

A localização geográfica da cidade de Ponte Nova na área em estudo, a sotavento da escarpa de São Geraldo, indica ser um dos fatores responsáveis pelos menores valores de umidade relativa do ar nela registrados.

Mas, os municípios de Visconde do Rio Branco e Ubá, situados a barlavento, vertentes voltadas contra a direção predominante do vento, favorecendo a ascensão forçada do ar e o surgimento de instabilidades locais, que podem ocasionar chuvas orográficas localizadas, não favorece amenização do clima, em razão da mesma estar inserida no golfão de Ubá.

\section{Considerações Finais}

O relevo pode interagir com as condições climáticas, diversificando os padrões climáticos, através da variação de altitude da superfície, da forma e orientação das vertentes.

Todavia, apesar de se observar, que a diferença altimétrica influencia as diferenças térmicas e higrométricas ao longo do perfil, a mesma não apresentou uma relação tão clara, quando realizado o gráfico de dispersão linear com a temperatura médias dos 4 dias de experimento com as respectivas altitudes dos pontos de amostra, como Falcão et. al. (2010) observou para umidade relativa do ar e Lima et. al. (2010) para temperatura do ar, ambos no Alto do Caparaó.

A não observância de tal relação, pode estar associada talvez a localização do transeto, a sotavento da serra do Brigadeiro, que serve de obstáculo 
para os ventos de leste, associado a forma do Golfão de Ubá, favoreça um ambiente de calmaria. Mas pode também haver uma maior interferência das escalas microclimáticas, associadas ao tipo de uso da terra.

\section{Nota}

Este trabalho encontra-se inserido no projeto de pesquisa: A importância do sítio no caráter climático nas cidades da Zona da Mata Mineira, registrado sob o número de registro-SISPPG-UFV: 10708259328, contando com apoio financeiro da Fundação Arthur Bernardes (FUNARBE), através do Programa FUNARPEX

\section{Agradecimentos}

- Ao CNPq pela concessão da Bolsa de Iniciação Científica ao acadêmico Rafael de Souza Alves, durante o período de execução da pesquisa.

- A FUNARBE através do Programa de bolsas de qualidade em pesquisa de excelência para jovens docentes pesquisadores (FUNARPEX) edital 2010/2011, que patrocina o projeto: $A$ Importância do sítio no caráter climático nas cidades localizadas na Zona da Mata Mineira.

- Aos acadêmicos: Carla de Souza Rocha, Ana Carolina Santos e Silva, Victor Carneiro, membros do Laboratório de Biogeografia e Climatologia (BIOCLIMA), que nos auxiliaram na realização dos experimentos de campo, no verão de 2011.

\section{REFERÊNCIAS}

.ABREU, M. L. Climatologia da estação chuvosa de Minas Gerais: de Nimer (1977) à Zona de convergência do atlântico sul. Geonomos, Belo Horizonte, v. 6, n. 2, p. 17-22, 1997. Disponível em: http://www.igc.ufmg.br/geonomos/PDFs/6_2_17_22_Abreu.pdf. Acesso em 9 Dez. 2011.

.AB'SÁBER, A. N. Os Domínios De Natureza No Brasil: Potencialidades Paisagísticas. São Paulo: Ateliê Editora, 2003.

.AMORIM, M. C. C. T. Ilhas de calor em Birigui-SP. Revista Brasileira de Climatologia, Presidente Prudente, v. 1, n. 1, p. 121-130, 2005.

.ANDRADE, M. C. Aspectos Geográficos da Região de Ubá. Anais da Associação dos Geógrafos Brasileiros, São Paulo, Avulso n. 1, 1961.

.ASSIS, W. L.; ABREU, M. L. O clima urbano de Belo Horizonte: Análise têmporo-espacial do campo térmico e hígrico. Revista de Ciências Humanas, Viçosa, v. 10, n.1, p. 47-63, 2010. Disponível em: http://www.cch.ufv.br/revista/pdfs/vol10/artigo3vol10-1.pdf. Acesso em 16 Dez. 2011

.BRANDÃO, A. M. P. M. As alterações climáticas na área metropolitana do Rio de Janeiro: uma provável influência do crescimento urbano. in: ABREU, M. A. (org.).: Natureza e sociedade no Rio de Janeiro. 3 ed. Rio de Janeiro: Secretaria municipal de cultura, turismo e esportes/Departamento geral de documentação e informação cultural, p. 143-191, 1992, 336p.

.BRANDÃO, A. M. P. M.; TARIFA, J. R. O campo térmico na cidade do Rio de Janeiro. In: ENCONTRO DE GEÓGRAFOS DA AMÉRICA LATINA., 6. 1995. Buenos Aires, Anais... Buenos Aires, $1995 . \quad$ Disponível em: http://observatoriogeograficoamericalatina.org.mx/egal6/Procesosambientales/Climatologia/8 67.pdf Acesso em 12 dez. 2011.

.BRANDÃO, A. M. P. M. O clima urbano da cidade do Rio de Janeiro. 362f. Tese (Doutorado em Geografia Física), Faculdade de Filosofia, Letras e Ciências Humanas, Programa de Pós-graduação em Geografia Física, USP, 1996.

.BRANDÃO, A. M. P. M. A ilha de calor de outono na cidade do Rio de Janeiro: configuração em situações sinóticas contrastantes. in: SANT'ANNA NETO, J. A.; ZAVATINI, J. A. (orgs.).: Variabilidade e mudanças climáticas: Implicações ambientais e socioeconômicas. Maringá: UEM, p. 193-210, 2001, 259p.

.COLLISCHONN, E.; FIALHO, E. S. Problematizando a inscrição sociocultural do pensamento "politicamente correto" em tempos de mudanças climáticas. Boletim Gaúcho de Geografia, Porto 
Alegre, n. 33, p. 191-214, 2007. Disponível em: http://agb-portoalegre.webnode.com.br/bgg-33/. Acesso em 9 Dez. 2011.

.DONATO, L Variações termo-higrométricas decorrentes das diferentes formas de uso do solo em uma cidade de pequeno porte - Barbosa Ferraz-PR. In: ENCUENTRO DE GEÓGRAFOS DA AMÉRICA LATINA, 9, EGAL: Anais..., . Montevidéu, Uruguai, 2009. Disponível em: http://egal2009.easyplanners.info/programaExtendido.php. Acesso em 17 jun. 2009.

.FALCÃO, R. M.; GALVANI, E.; LIMA, N. G. B.; CRUZ, B. R. P. Análise da variação da umidade relativa do ar do pico da bandeira, Parque Nacional Alto Caparaó, Brasil. In: SEMINÁRIO LATINO-AMERICANO DE GEOGAFIA FÍSICA E SEMINÁRIO IBERO-AMERICANO DE GEOGRAFIA FÍSICA, $6, \quad 2 . \quad$ Coimbra, 2010.2 Disponível em: http://www.uc.pt/fluc/cegot/VISLAGF/actas/tema3/rita_falcao. Acesso em 21 Dez 2011.

.FERREIRA, J. H. D.; NERY, J. T. Análise de componentes principais da precipitação do estado de Minas Gerais. In: CONGRESSO BRASILEIRO DE METEOROLOGIA, 12, 2002, Foz do Iguaçu, Anais... Disponível em: http://www.cbmet.com/edicoes.php?cgid=11. Acesso em: $11 \mathrm{dez}$. 2011.

.FIALHO, E. S. Análise temporoespacial do campo térmico na Ilha do Governador-RJ em situações sazonais de verão e inverno. 164f. Dissertação (Mestrado em Geografia) - Centro de Ciências Matemáticas e da Natureza - Instituto de Geociências-UFRJ, Rio de Janeiro, 2002.

.FIALHO, E. S. Ilha de calor em cidade de pequeno porte: Caso de Viçosa, na Zona da Mata Mineira. 259f. Tese (Doutorado em Geografia Física) Faculdade de Filosofia, Ciência, Letras e Ciências Humanas, USP, São Paulo, 2009.

FIALHO, E. S.; SOUZA, J. J. L. L. Utilização do clima no planejamento com reflexo das condições ambientais nos .centros urbanos. Acta Geográfica, Boa Vista, v. 1, n. 2, p. 29-41, 2007. Disponível em: http://ufrr.br/revista/index.php/actageo/article/viewFile/175/352. Acesso em 9 Dez. 2011.

.FIALHO, E. S. Práticas do ensino de climatologia através da observação sensível. Revista Ágora, Santa Cruz do Sul, v. 13, n. 1, p. 105-123, 2007. Disponível em: http://online.unisc.br/seer/index.php/agora/article/viewFile/112/71. Acesso em 10 Dez. 2011.

.FIALHO, E. S. Unidades climáticas urbana: O caso da Ilha do Governador-RJ. Revista de

Ciências Humanas, Viçosa, v. 10, n. 1, p. 26-46, 2010. Disponível em:

http://www.cch.ufv.br/revista/pdfs/vol10/artigo2vol10-1.pdf. Acesso em 17 Dez. 2011.

.FRITZSONS, E.; MANTOVANI, L. E.; AGUIAR, A. V. Relação entre altitude e temperatura: Uma contribuição ao zoneamento climático no estado do Paraná. Revista de Estudos Ambientais, Blumenau, v. 10, n. 1, p. 49-64, 2008 . Disponível em: http://proxy.furb.br/ojs/index.php/rea/article/view/902/681. Acesso em 21 Dez. 2011.

.GALVANI, E.; LMA, N. G. B.; SERAFINI Jr, S.; Alves, R. R. Relação entre umidade relativa do ar, cobertura vegetal e uso do solo no Parque Estadual de Intervales (PEI) e seu entorno, São Paulo, Brasil. In: ENCONTRO DE GEÓGRAFOS DA AMÉRICA LATINA - EGAL, 12, 2009, Montevideo. Caminhando por uma América Latina em transformação. Montevideo: Easy Planers, 2009. Anais... Disponível em: <http://egal2009.easyplanners.info/area04/4052_Galvani_Emerson.doc>. Acesso em 21 Dez. 2011.

.GEIGER, R. Manual de microclimatologia: O clima da camada de ar junto ao solo. 4. ed. Tradução de Ivone Gouveia. Lisboa: Fundação Calouste Gulbenkian, 1961, 556p.

J.ARDIM, C. H. Variações da temperatura do ar e o papel das áreas verdes nas pesquisas de climatologia urbana. Revista de Ciências Humanas, Viçosa, v. 10, n. 1, p. 9-25, 2010.

.JARDIM, C. H.; FERREIRA, M. A Correlação dos fatos geográficos em climatologia a partir da noção de "sítio" e "situação". In: ENCONTRO DE GEÓGRAFOS DA AMÉRICA LATINA., 10. 2005. São Paulo, Anais..., São Paulo: USP, 2005. Disponível em: http://observatoriogeograficoamericalatina.org.mx/egal10/Procesosambientales/Climatologia/ 06.pdf Acesso em 2 dez. 2011.

.JARDIM, C. H. Variações da temperatura do ar e o papel das áreas verdes nas pesquisas de climatologia urbana. Revista de Ciências Humanas, Viçosa, v. 10, n.1, p. 9-25, 2010. Disponível em: http://www.cch.ufv.br/revista/pdfs/vol10/artigo1vol10-1.pdf. Acesso em 3 Nov. 2011.

.LANDSBERG, H. E. O clima das cidades. Revista do Departamento de Geografia, São Paulo, v. 18, p. 95-111, 2006. Disponível em: http://citrus.uspnet.usp.br/rdg/ojs/index.php/rdg/article/view/73/62. Acesso em 10 Dez. 2011.

.LIMA, N. G. B.; GALVANI, E.; FALCÃO, R. Análise da temperatura do ar no perfil topoclimático do Pico da Bandeira, Parque Nacional Alto Caparaó, Brasil, entre as altitudes de $1106 \mathrm{~m}$ a $2982 \mathrm{~m}$. In: SEMINÁRIO LATINO-AMERICANO DE GEOGAFIA FÍSICA E SEMINÁRIO IBEROAMERICANO DE GEOGRAFIA FÍSICA, 6, 2. Coimbra, 2010. Anais..., Disponível em: http://www.uc.pt/fluc/cegot/VISLAGF/actas/tema3/nadia_gilma. Acesso em 21 Dez 2011.

.NUNES, W. A. G. A.; KER, J. C.; SCHAEFER, C. E. G. R.; FERNANDES FILHO, E. I.; GOMES, F. H. Relação solo-paisagem-material de origem e gênese de alguns solos no domínio do "Mar de 
Morros", Minas Gerais. Revista Brasileira de Ciência do Solo, Viçosa, n. 25, p. 341-354, 2001.

.MARCHI, O. A. M.; CALIJURI, M. L.; COSTA, S. H. G. ; LUGÃO, W. G.; SOUZA, P. J. A. Leitura e caracterização da paisagem em auxílio ao planejamento da ocupação urbana de Ponte Nova - MG. Natureza \& Desenvolvimento, Viçosa, v. 1, n. 1, p. 41-50, 2005.

.MENDONÇA, F. O Clima urbano de cidades de porte médio e pequeno: aspectos teóricometodológicos e estudo de caso. In: SANT'ANNA NETO, J. L.; ZAVATINI, J. A. (orgs). Variabilidade e Mudanças Climáticas: implicações ambientais e socioeconômicas. Maringá: Eduem, p. 167-192, 2000.

Clima e planejamento urbano em londrina: proposição metodológica e de intervenção urbana a partir do estudo do campo termo-higrométrico. In: MONTEIRO, C. A. F.; MENDONÇA, F. (orgs). Clima urbano. São Paulo: Contexto, p. 93-120, 2003a.

. O estudo do clima urbano no Brasil: evolução, tendências e alguns desafios. In: MONTEIRO, C. A. F.; MENDONÇA, F. (orgs). Clima urbano. São Paulo: Contexto, p. 175192, 2003b.

.MINAKI, C.; AMORIM, M. C. C. T. Comparação da temperatura e da umidade relativa do ar na área urbana e rural de Guararapes-SP. In: SIMPÓSIO BRASILEIRO DE GEOGRAFIA FÍSICA APLICADA, 11, 2005. São Paulo. Anais..., São Paulo: USP, 2005, cd-rom.

.MONTEIRO, C. A. F. Teoria e clima urbano: um projeto e seus caminhos. In: MONTEIRO, C. A. F.; MENDONÇA, F. (orgs). Clima Urbano. São Paulo: Contexto, p. 9-67, 2003.

.MONTEIRO, C. A. F. A cidade como processo derivador ambiental e a geração de um clima urbano - estratégias na abordagem geográfica. Geosul, Florianópolis, v. 5, n. 9, p. 80-114, 1990.

.MORA, C. Padrões térmicos no alto vale do Zêzere. Condicionantes topográficas e meteorológicas. Finisterra, Lisboa, v. 44, n. 87, p. 55-69, 2009. Disponível em: http://www.ceg.ul.pt/finisterra/numeros/2009-87/87_05.pdf. Acesso em 21 Dez. 2011

.ROCHA, V. M.; FIALHO, E. S. Uso da terra e suas Implicações na Variação Termo-Higrométrico ao longo de um Transeto Campo-Cidade no Município de Viçosa-MG. Revista de Ciências Humanas, Viçosa, v. 10, n. 1, p. 64-77, jan./jun. 2010. Disponível em: http://www.cch.ufv.br/revista/pdfs/vol10/artigo4vol10-1.pdf. Acesso em 17 Dez. 2011.

.ROSSATO, P. S. O sistema termodinâmico do clima urbano de Nova Palma, RS: contribuição ao clima urbano de cidades pequenas. 119 f. Dissertação (Mestrado em Geografia) - Universidade Federal de Santa Maria, Santa Maria, RS, 2010.

.VALVERDE, O. Estudo regional da Zona da Mata de Minas Gerais. Revista Brasileira de Geografia, Rio de Janeiro, v. 20, n. 1, p. 3-82, 1958.

.VIANA, S. S. M.; AMORIM, M. C. C. T. Caracterização do clima urbano em Teodoro SampaioSP: Uma introdução. Revista Sociedade e Natureza, Uberlândia, v. 20, n. 2, p. 19-42, 2008. Disponível em: http://www.scielo.br/pdf/sn/v20n2/a02v20n2.pdf. Acesso em 19 Dez. 2011.

.SANT'ANNA NETO, J. L. Decálogo da climatologia do sudeste brasileiro. Revista Brasileira de Climatologia, São Paulo, v. 1, n. 1, p. 43-60, 2005. Disponível em:http://ojs.c3sl.ufpr.br/ojs2/index.php/revistaabclima/article/viewFile/25232/16936.

Acesso em 15 Dez. 2011.

.SEZERINO, M. L.; MONTEIRO, C. A. F. O campo térmico na cidade de Florianópolis: Primeiros experimentos. Geosul, Florianópolis, v. 5, n. 9, p. 20-60, 1990. Disponível em: http://www.periodicos.ufsc.br/index.php/geosul/article/view/12738/11904. Acesso em 15 Dez. 2011. .ZAMPARONI, C. A. G. P. Ilha de calor em Barra do Bugres e Tangará da Serra-MT: Uma contribuição ao estudo do clima urbano em cidades de pequeno porte em área tropical. 1995. 99f. Dissertação (Mestrado em Geografia Física). Faculdade de Filosofia. Letras e Ciências Humanas. Programa de Pós-graduação em Geografia Física, USP, 1995. 